\title{
Radiological Aspects of BRONJ after Dental Extractions in Ovariectomized Female Wistar Rats
}

\author{
Adela Cristina LAZĂR ${ }^{1 *}$, Radu LĂCĂTUȘ ${ }^{2}$, Robert PURDOIU ${ }^{2}$, Lucia BEL ${ }^{3}$, Orsolya SARPATAKI ${ }^{3}$, Mariana \\ PĂCURAR $^{4}$, Radu-Septimiu CÂMPIAN ${ }^{1}$
}

Department of Oral Rehabilitation, Health and Management of Dental office, Faculty of Dental Medicine, "Iuliu Hatieganu" University,15 Victor Babes str, Cluj-Napoca, Romania

Department of Semiology and Medical Imaging, Ethiopathology, Radiology and Radiation Protection, University of Agricultural science and Veterinary Medicine, 3-5 Calea Manastur, Cluj-Napoca, Romania Department of Physiopathology, Biologia Growth and Pathology Laboratory Animals, University of Agricultural Science and Veterinary Medicine, 3-5 Calea Manastur, Cluj-Napoca, Romania Department MD1 Orthodonthics, University of Medicine and Pharmacy Tirgu-Mureș, 38 Gheorghe Marinescu str, Tirgu-Mures, Romania *corresponding author: lazar_adela@yahoo.ro

Bulletin UASVM Veterinary Medicine 75(1)/2018

Print ISSN 1843-5270; Electronic ISSN 1843-5378

doi:10.15835/buasvmcn-vm:002017

\begin{abstract}
Experimental study in animal model - female Wistar rats - using two types of bisphosphonates (ibandronic acid and denosumab) for treating osteoporosis induced by ovariectomy, performing extractions in the maxillary central incisors and occurance of bisphosphonates related osteonecrosis of the jaw (BRONJ) after the dental extractions. The appearance of BRONJ in female Wistar rats which had undergone ovariectomy in advance and received two types of bisphosphonates and a comparison between 3 groups show that BRONJ it is first diagnosticated radiological, before it is first signs in oral cavity. Therefore, careful monitoring of patients undergoing bisphosphonate therapy is essential in the clear and accurate diagnosis of BRONJ. According to the experiment conducted by us, the administration of this class of bisphosphonates has antibacterial effects, decrease osteoclasts activity and thus decrease the bone resorption, but as a secondary main effect it induces BRONJ after performing routine dental surgeries.
\end{abstract}

Keywords: bisphosphonates, BRONJ, dental extractions, lamina dura, ovariectomy

\section{Introduction}

Bisphosphonates represent the category of drugs most commonly used in the treatment of osteoporosis in postmenopausal women with this disease (Melton et al., 1992), as well as in the treatment of bone metastases in prostate carcinomas (Coxon et al., 2004), bone metastases in multiple myeloma (Berenson, 1996; Hortobagyi et al., 2007), patients receiving high-dose corticosteroids for various conditions (Graham, 1992), and according to new studies, can also be administered to children with imperfect osteogenesis (Graham, 1992). The bone is continuously trained throughout life, being constantly changing. There is a constant balance between bone resorption and bone recovery, aided by osteoblast cells and osteoclasts. When this balance is disturbed by systemic diseases (osteoporosis), there are changes in bone geometry (at the level of hydroxyapatite). Osteoblasts form a bone matrix (collagen or non-collagen) called osteoid. They can remain on the bone surface by performing bone apoptosis (Tripton et al., 2010). Osteoclasts are formed from hematopoietic cells of monocytes or macrophages. During bone resorption, hydroxyapatite and organic matrix are removed by the multinucleated osteoclasts. Both bone deposition and bone resorption are coordinated and controlled by endocrine and biological mediators mediating stimulation 
(Parathyroid Hormon PTH, Parathyroid-related peptide Rpth, Prostaglandine E2, Vitamin D3) and inhibition (Calcitonin, Estrogen, Interferon, Transforming growth factor B) (Frank et al., 2001; Lewiecki, 2010). Bone metabolism is regulated by RANK (receptor-activated nuclear factor $K \beta$ ), RANKL (receptor-activated nuclear factor $\mathrm{K} \beta$ ligand) and OPG (osteoprotegrin). The balance between RANKL and OPG is crucial in the control of osteoclasts in the bone microclimate. RANK is expressed in the cell membrane plasma of osteoclasts, RANKL is expressed in the cellular plasma membrane plasma of osteoblasts and OPG is produced by osteoblasts acting as a receptor decoding its RANKL binding, thus preventing RANK action (Sarina et al., 2010).

Osteoporosis is defined as a bone cell disorder characterized by a decrease in bone mass and bone tissue integrity, resulting in frailty and decreased bone hardness. This decrease in bone cell performance leads to an increased risk of fractures with hip and spinal predisposition. Percentage of osteoporosis appears to be $40 \%$ in postmenopausal women and $15 \%$ in elderly men (Genant et al., 2010). According to recent studies, estrogen deficiency is the main contributing factor in the formation of osteoporosis in both women and men (McClung et al., 2006). The estrogen deficiency present at an advanced age is associated with increased bone resorption at the expense of bone formation, this phenomenon leading to excessive bone loss. From a molecular point of view, it has recently been discovered that the nuclear receptor activator $\mathrm{k} \beta$ (RANK) / RANK ligand RANKL / Osteoprotegerin (OPG) triggers an important signal that regulates osteoclast formation. Thus, the RANK / RANKL binding inhibits the formation and differentiation of osteoclasts and implicitly slows bone resorption (Bone et al., 2008). Recent studies have shown that regulation of bone cell RANKL activity and estrogen deficiency in postmenopausal women are responsible for bone resorption (Frank et al., 2001; Miller et al., 2010). Furthermore, some experiments performed on the animal model (ovariectomized mice) to induce osteoporosis have shown that OPG, in addition to preventing bone resorption, also increases bone mineral density, excessively leading to osteopetrosis. It has been demonstrated that a single dose of OPG injectable in postmenopausal women may result in a rapid and profound reduction in bone turnover over even 12 hours; This fact could be demonstrated by biochemical markers and collagen products (NTX urinary N-telopeptide, DPD deoxypyridinoline) (Dilep et al., 2013; Petcu et al., 2013).

The mechanism of action of bisphosphonates is not fully understood. According to research conducted so far, bisphosphonates can induce apoptosis in osteoclasts. Injectable bisphosphonate formulations have direct action on osteocytes, producing their lysis. Bisphosphonates alter the production of RANKL and OPG, leading to a decrease in bone resorption (Sarasquete et al., 2009).

The first types of bisphosphonates appeared between 1970-1980 and were used successfully in diseases with bone mineral imbalance (osteocytes marked osteoblast activity) and low calcium absorption in bone hydroxyapatite (osteoporosis). These include etidronate, clodronate and pamidronate. Over the years and research in this field has evolved, the same category of pharmaceuticals and nonidronate, risendronate, zolendronate, minodronate, alendronate and ibandronate (Marx et al., 2003) have joined. Since only two types of bisphosphonates (ibandronic acid and denosumab) have been used in the present study, I will continue to discuss some of the literature on this issue.

Denosumab, from a molecular point of view, is a human monoclonal antibody that acts by inhibiting RANK NF-k $\beta$ ligand RANKL, being a cytokine of the TNF family and the primary mediator of bone resorption (osteoclasts). By linking to RANKL, Denosumab prevents RANK activation. This phenomenon leads to inhibition of osteoclast maturation, decrease in their function and subsequently inhibition of bone resorption (Bilezikian 2006; Federico et al., 2001). Clinically, patients are given subcutaneous injection two times every 6 months at a dose of $60-120 \mathrm{mg}$ (Torres et al., 2011; Yamashita et al., 2012). Its effect translates into a significant and rapid reduction in bone turnover associated with a bone mineral density (DXA) in women with this diminished appearance (Van der Wyngaert et al., 2006; Assoulino-Dayar et al., 2002; Capsoni et al., 2006).

Administering bisphosphonates involves both benefits and risks. Their benefits and advantages have been exposed previously. Risk-related, like 
any drug, bisphosphonates also have side effects such as burning sensation, erosive esophagitis associated with dysphagia, oesophageal stenosis, uveitis, gastric ulceration and abdominal pain, oesophageal mucosal ulceration. When pseudoflue syndrome (ie fever, chills, myalgia, atralgia, bone pain), phlebitis, anemia, fatigue, general weakness, edema, dyspnea (Nicolau et al., 2012; Whute 2010; Wilfried et al., 2005-2006) occurs, it is recommended that the patient receiving the bisphosphonate treatment to be monitored by the treatingphysiciant. Themostcommon complication is bone necrosis localized predominantly in the jaw bone (ONJ). This pathological entity appears in a very large percentage at patients receiving intravenous bisphosphonate therapy (Paula et al., 2012; Sanna et al., 2006). These issues raised great questions about the safety of bisphosphonates administered to patients with osteoporosis. From a clinical point of view, the $\mathrm{ONJ}$ is presented as an exposed, hypodinamic bone area with decreasing biomechanical skills, tissue dehiscence, chronic bone dehiscence, hypocellularity, radiologically observed bone lysis (Lab.Corp.America 2010; Fischbach 2009) localized to the jaw bone, mandibular or palate with a Delayed or nonhealing for a period of 6-8 weeks (Wallach 2001; Del Castillo et al., 2007), with several stages of evolution. In $80 \%$ of cases, the lesions are painful and are characterized by a burning sensation, and $69 \%$ of cases occur after dental extraction surgery or other alveolar dental surgery (Lothan 1998). The BRONJ is not a new pathological entity; In the past, the development of mandibular bone lesions has been associated with head and neck irradiation, osteomyelitis and even corticosteroid treatment (Wallach 2001; Franketal et al., 2012).

For clear and accurate screening of the BRONJ and its stages of development, X-ray (OPT, Panoramic X-ray) is used where thick lamellar thickening, osteosclerosis, osteolysis, diffuse sclerosis, subperiosteal bone deposits, postoperative bone remodeling (Pighon et al., 2010; Sankar et al., 2014; Lazar et al., 2016), CBCT (ComputerTomography), their major advantage is the 3D access of bone structures at a very good resolution. Radiation exposure is higher than at OPT, but lower than MSTT (Multisliced Computer Tomography) (Pighon et al., 2010). A correlation between the two related to sensitivity in the $\mathrm{ONJ}$ diagnosis indicates that Panoramic X-rays tend to undermine the lesion extension and even omit the presence of small bone seizures (Lazar et al., 2016).

\section{Material and method}

The present study aims to expose an experimental comparison done on the animal model - females wistar mice - between two types of bisphosphonates (ibandronic acid and denosumab), in the conditions of osteoporosis induced by ovariectomy, performing extractions at the superior central inaccuracies and the occurrence of osteonecrosis of the jaw bone. The main purpose of this experiment was to observe the occurrence of maxillary bone necrosis as a side effect of the administration of bisphosphonates under the conditions of dental extractions. The results obtained come to the help of dental practitioners who meet in current practice with patients with osteoporosis who are not only being treated or have completed bisphosphonate treatment and the appropriate dental treatment plan in these cases.

The purpose of this research (Lazar et al., 2016) is to observe the positive and negative effects of bisphosphonates and denosumab on the maxillary bones in dental surgical dental conditions in rats with induced osteoporosis. The experiment described in this article was conducted at the Biomass UMF Cluj-Napoca and in the USAMV Cluj-Napoca experimental laboratories complying with the standards and directives imposed by the Ethics Commission in line with Law 43/2014 (published in the Official Gazette, Part I no.326 Of 6 May 2014) on the protection of animals used for scientific purposes.

\section{Animal management}

Females of 30 wistar mice were purchased through UMF Cluj-Napoca, each weighing 180$200 \mathrm{~g}$ with an average age of 8 weeks. 5 mice were stored in special boxes (Fig.4), which were cleaned every day. The light-dark cycle (12:12 h) began at $6: 00$, the room temperature kept constant at 20$23^{\circ}$ C. All mice received appropriate nutrition (pellet rat chow) following the nutritional values (12\% fat, $63.2 \%$ carbohydrates, $24.3 \%$ protein) required for mice and unlimited access from fresh bottles to fresh water (Marx 2003). 


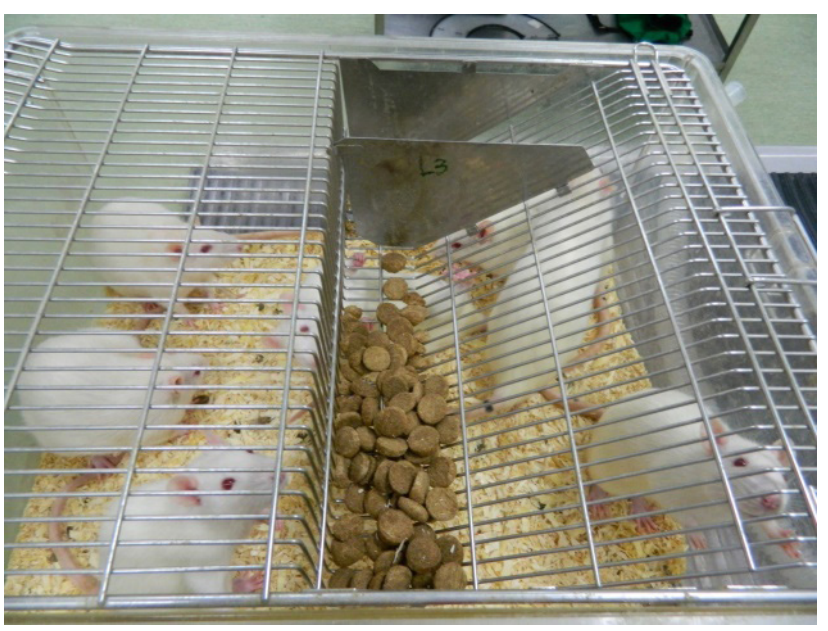

Figure 1. Proper storage of experimental rats

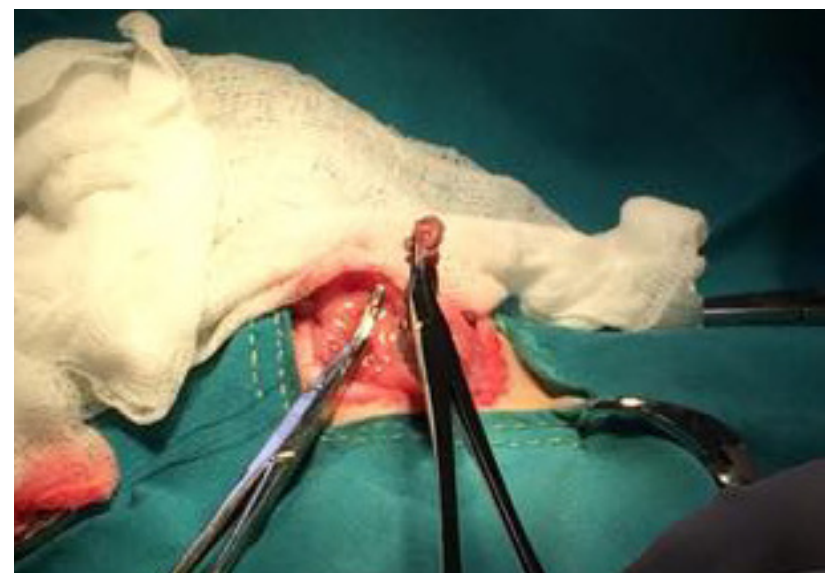

Figure 3. Intraoperative imaging of the ovary after extirpation

\section{Osteoporosis induced by ovariectomy}

Ovariectomy began by sedation of mice using a combination of xylazine $5.00 \mathrm{mg} / \mathrm{kg}$ body weight and ketamind hydrochloride $50.00 \mathrm{mg} / \mathrm{kg}$ body weight intramuscularly. The mid-caudal ventral ventricle of the third pair of mammary livers was breed and cleansed with chloramine and alcohol disinfectant solution. A $2 \mathrm{~cm}$ incision (http:// www.fda.gov/downloads/ advisorycommittees/ committeesmeetingmaterials / d rug s / oncologicdrugsadvisorycommittee/ ucm250379. pdf. Acessed September 7, 2015) was performed, the skin was separated from the muscle and the ovaries exposed (Fig. 2). These were extirpated (Fig. 3) using a special ophthalmic catheter. After removal of the ovaries, the peritoneum and the white line were closed with a 3.0-threaded suture thread in continuous thread and a 4.0-threaded

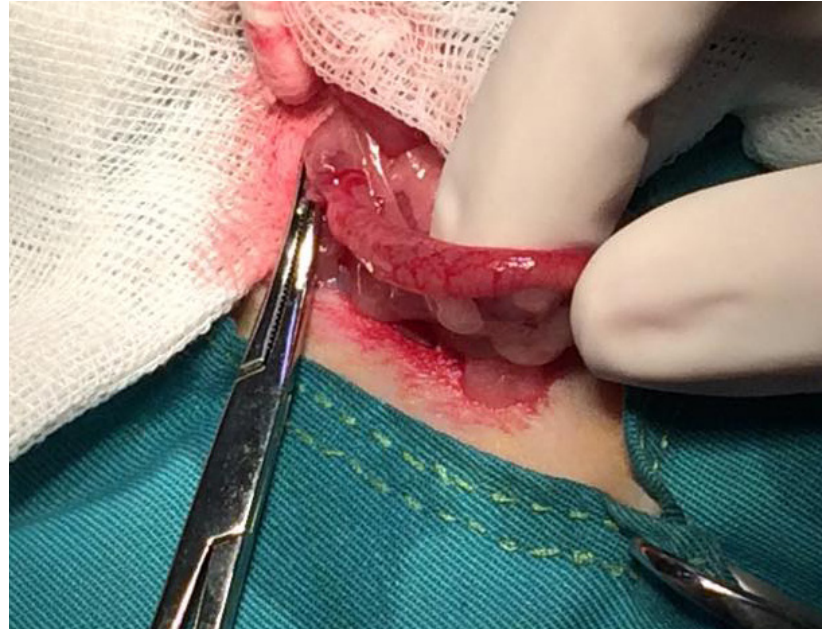

Figure 2. Intraoperative image, highlighting the ovary to be extirpated

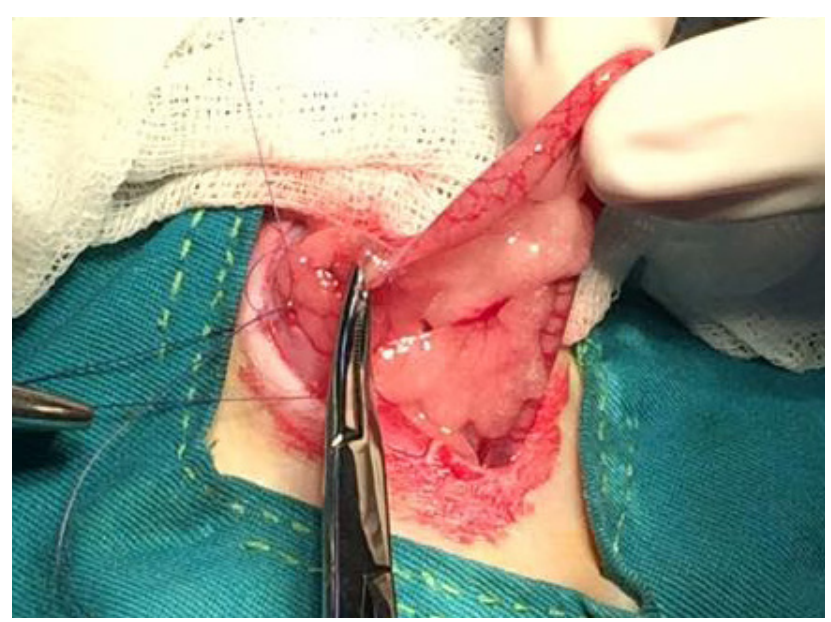

Figure 4. Intraoperative image, postovarectomy suture

cut suture resorbable at separate points (Van Breukelen 1982; Lipton et al., 2004) (Fig. 4). The operator, mice were coated with gauze bandage to avoid hypothermia (42) and antibiotic and antiinflammatory treatment was administered.

The operative protocol was performed on February 3, 2015, and for a period of 3 months (28 May 2015) the occurrence of osteoporosis was observed by serial radiography. During this period, 6 rats died due to internal haemorrhages (Sabrini et al., 1992) or possibly sepsis (Mulligan et al., 2005).

At the end of the 3-month period we remained with 24 healthy rats. Based on the exposures and radiologicalresults, theoccurrence of boneeruption in the humerus was observed in approximately all rats. The next step of the experiment was the 


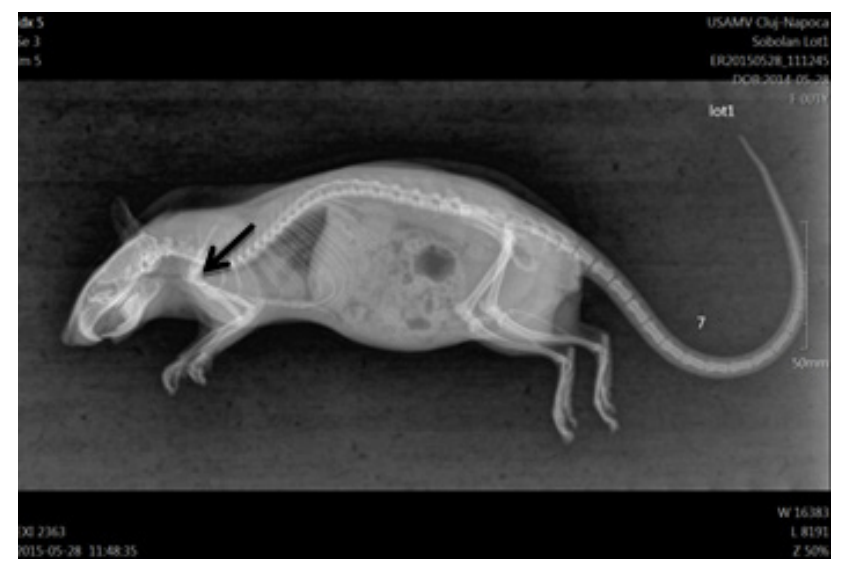

Figure 5. Initial radiological image of a rat in the 1 to 3 months from the onset of osteoporosis (black arrow - the presence of the bone in the humerus)

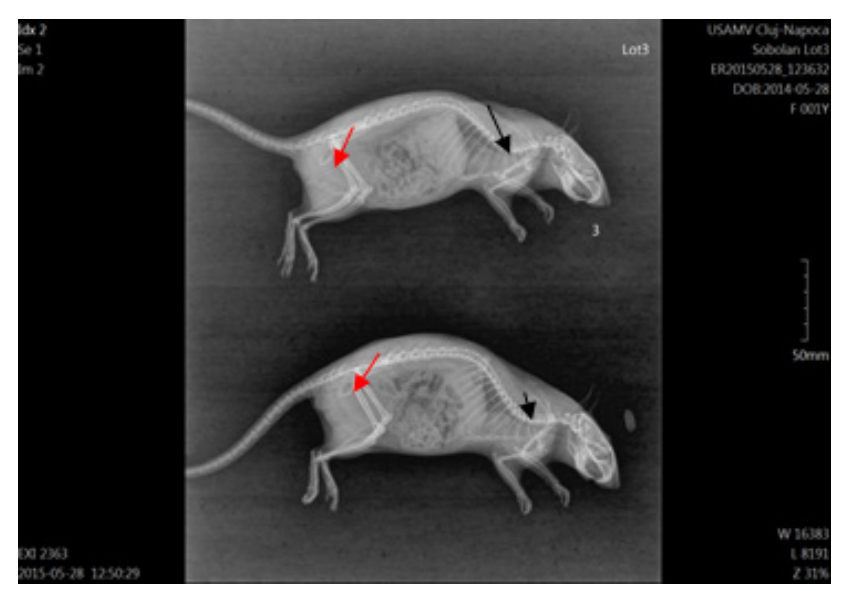

Figure 7. Initial radiological imaging of two rats from group 3 at 3 months after induction of osteoporosis (black arrow - bone in the humerus, red arrow - bone marrow scarring in the femur)

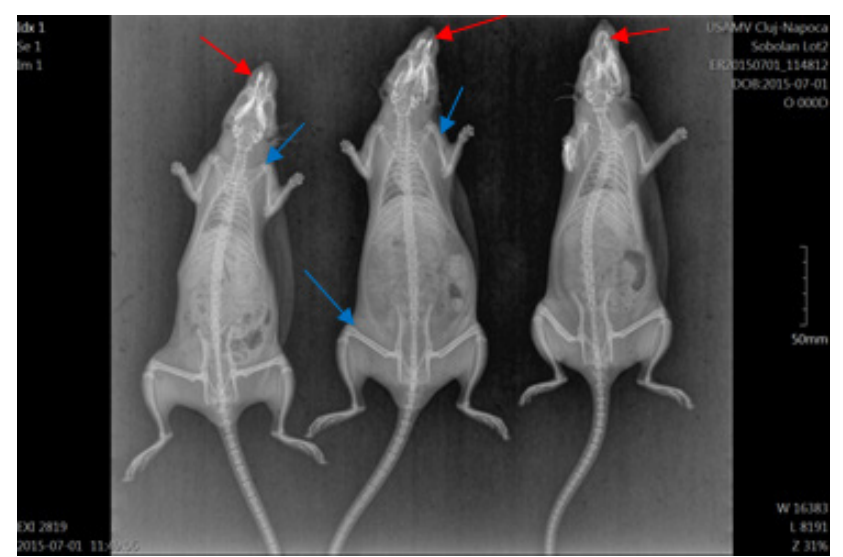

Figure 9. Radiological image 14 days after denosumab administration (lot 2) (red arrow - bone osteonecrosis in the postexcular alveolus, blue arrow - increase in bone density in the humerus and femur)

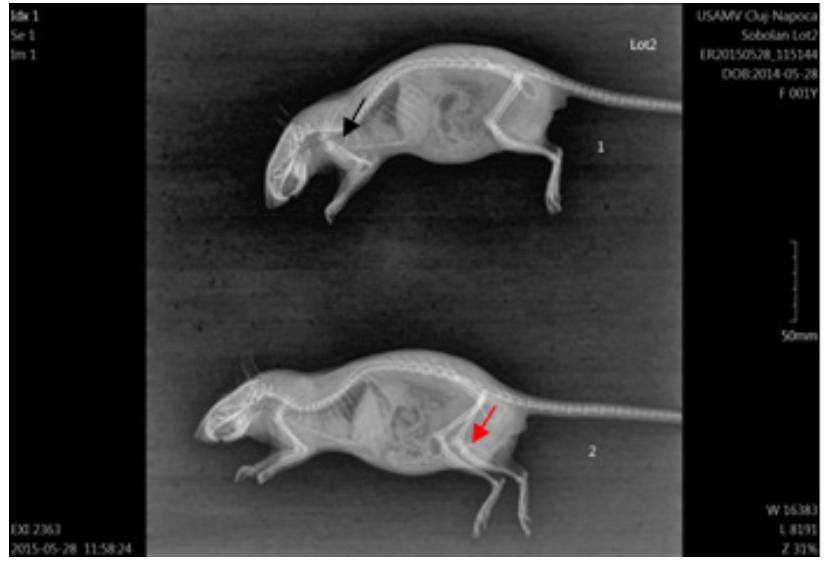

Figure 6. Initial radiological image of two rats from group 2 to 3 months after induction of osteoporosis (black toothbrush - bone growth in the humerus, red arrow - bone fracture in the femur)

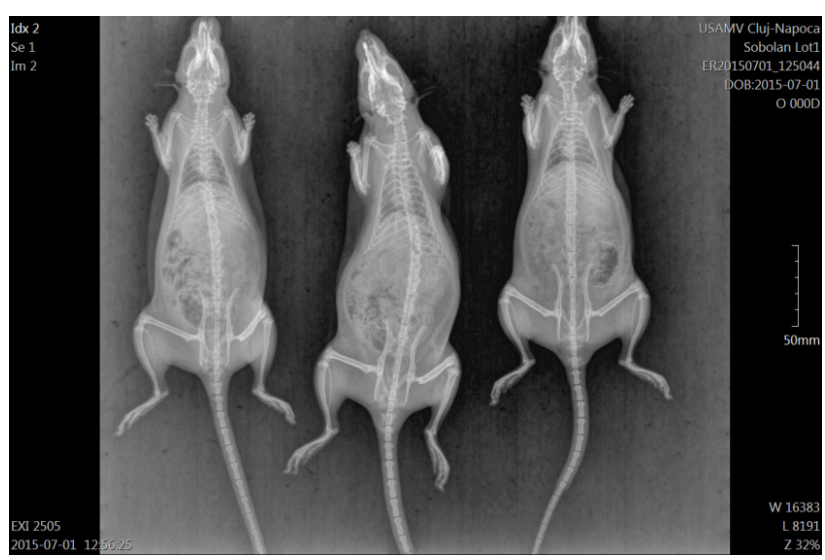

Figure 8. Radiological image 14 days after ibandronic acid administration (batch 1) (red arrow - bone osteonecrosis in the postexcular alveolus, blue arrow increase in bone density in the femur)

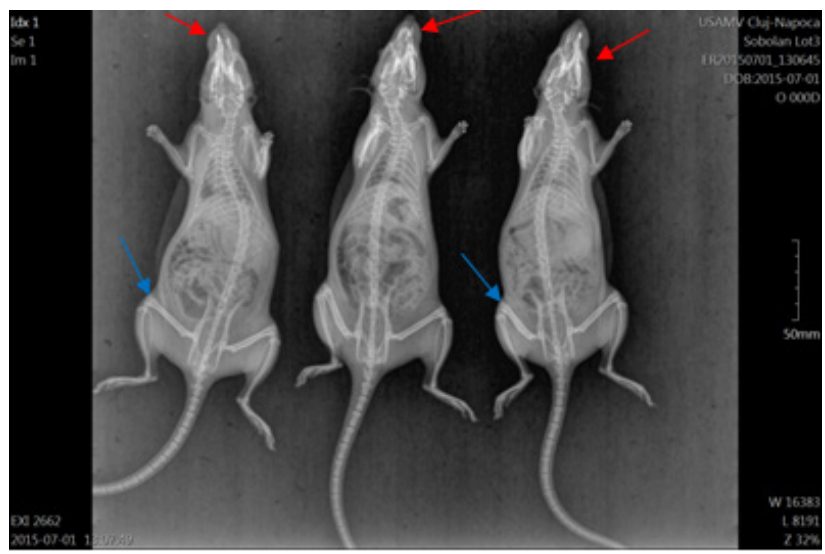

Figure 10. Radiological image at 14 days post physiological saline (control batch 3) (red arrow bone osteonecrosis in postextractional alveolus, blue arrow - signs of advanced osteoporosis) 


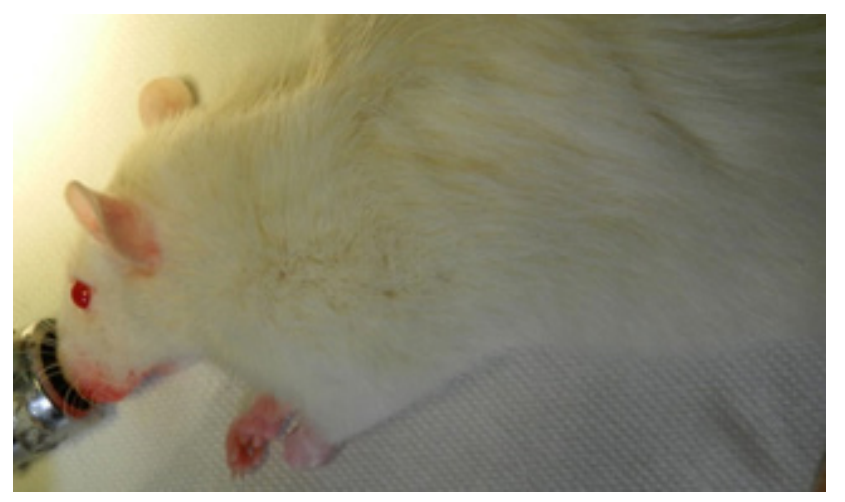

Figure 11. Preoperative anesthesia by inhalation

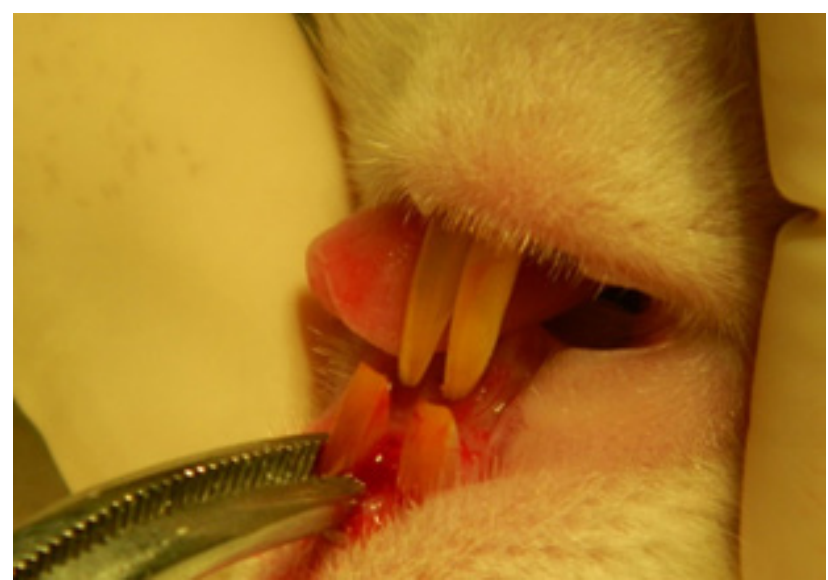

Figure 13. The actual dental extraction with a portac

administration of bisphosphonates and the followup of radiological and blood parameters

Thus, we divided the rats into three lots: group 1-8 rats, group 2-8 rats, group 3-7 rats. Prior to the administration of bisphosphonates, blood samples were taken from each rat from the infraorbital (approximately $25.6 \mathrm{ml}$ of blood) to determine alkaline phosphatase and creatinine (with normal creatinine values of $0.03-0.9 \mathrm{ml} / \mathrm{dl}$ and alkaline phosphatase 0-130 IU / i (Coxon et al., 2004), and $\mathrm{x}$-rays were performed in all rats. Subsequently, the lots were divided: Lot 1 - Ibandronic acid administration (OSAGRAND 3mg / 3ml single ampoule, fractionated $0.025 \mathrm{ml}$ soil. Ibandronic acid, $0.125 \mathrm{ml}$ physiological saline so that $0.150 \mathrm{ml}$ was administered per rat), lot 2 - administration of denosumab (PROLIA $60 \mathrm{mg}$ solution for injection in the pre-filled syringe, fractionated $0.025 \mathrm{ml}$ denosumab salt, $0.125 \mathrm{ml}$ physiological saline so that One $0.150 \mathrm{ml}$ was administered to each rat), and group 3 - the placebo group received 0.15

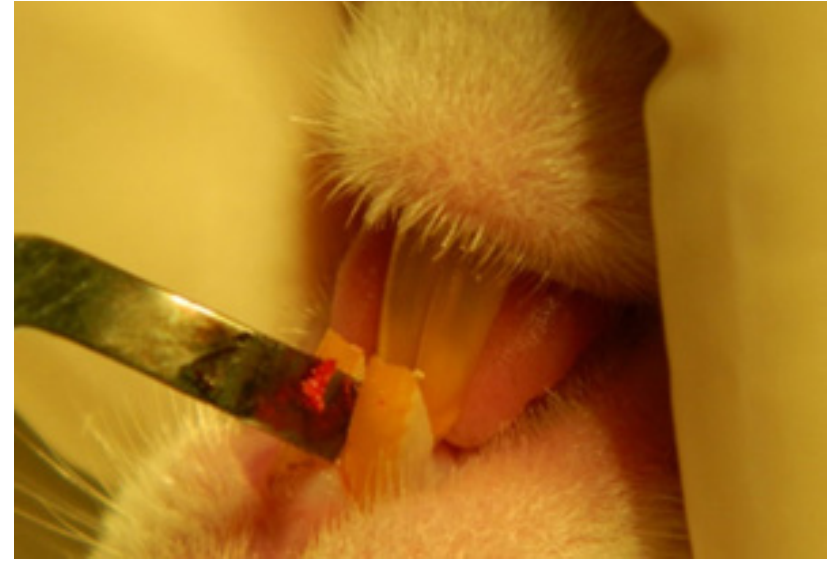

Figure 12. Removing the central incisor with a mouthpiece

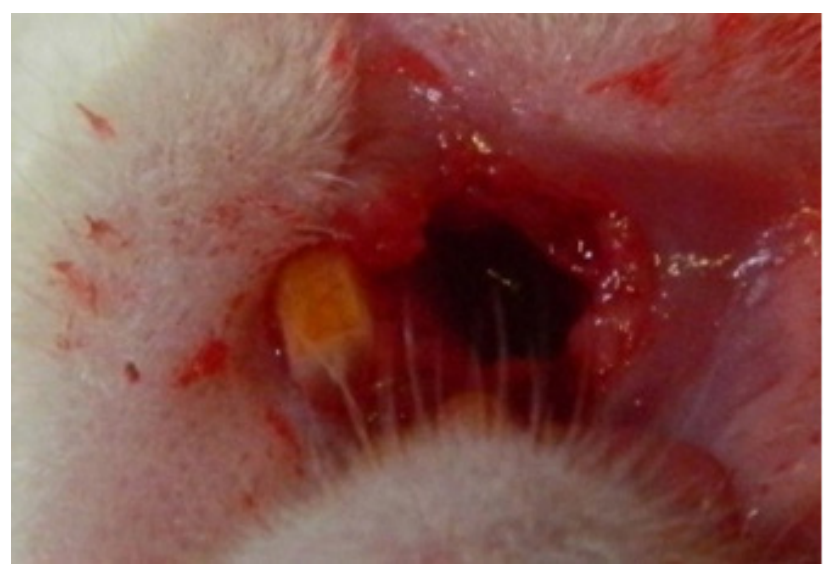

Figure 14. Post-surgical cage, frontal view

physiological serum. Expected 7 days and then a new set of radiological and breast tests Gvines for observing changes after treatment.

Twenty days after the first radiological exposure, a new set of blood and radiological assays was performed to benchmark these parameters. Dental extractions (extraction of the upper central incisor / rat) were performed every 20 days in each batch of rats.

\section{Management of dental extraction}

Sedation by intraperitoneal anesthesia with subst. Xylazin bio $2 \%$,, vetased $5 \mathrm{mg} / \mathrm{kg}, 50 \mathrm{mg}$ ketamine. Sindesomotomy was performed with a spatula and extraction of the upper central incisor by means of a small size hemostatic tweezer. Suture with resorbable suture thread 5.0. Compression with local buffer for haemostasis. Postoperatively, the animals were kept in a stable and clean environment, and antibiotics were not administered just aseptic surgery. 


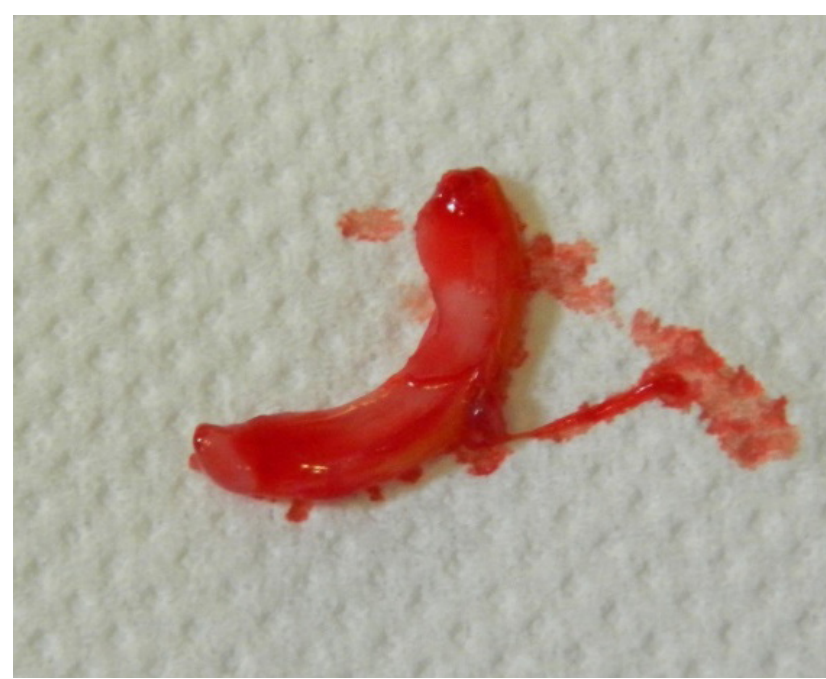

Figure 15. The postextractional aspect of the upper central incisor

At 34 days after the first exposure, a new set of blood and radiological analyzes was performed to detect the occurrence of osteonecrosis of the jaw bone. For this, inhalation anesthesia was performed with isoflurane ( 5 liters gas, 2 liters of oxygen) in the anesthetic cage. After performing routine analyzes, rats were euthanized by prolonged exposure to isofluorane until death was observed.

\section{Results and discussions}

During the experiment, blood samples (PAL, Creatinine) and rat exposures were made. Thus, 3 months after the ovariectomy procedure of each rat, a blood sampling and radiological sampling was performed for each rat in each batch. Data obtained from blood samples of alkaline phosphatase ALP (U / L) and Creatinine (mg / dl) performed over a period of 7, 14, 30 days on the three batches under conditions of administration of the two types of bisphosphonates (ibandronic acid, denosumab) were centralized in the following charts and tables. The ANOVA test was performed to compare the values between batches if there are significant differences or not, and the correlations are of the REGRESION type, where $\mathrm{R}^{2}$ shows correlations between the values obtained on each graph.

It is noted that ALP decreases at 7, 14, 30 days, under conditions of induced osteoporosis, which means that the administration of ibandronic acid changes these values.

Administration of denosumab (Prolia) in lot 2 has oscillating values for alkaline phosphatase

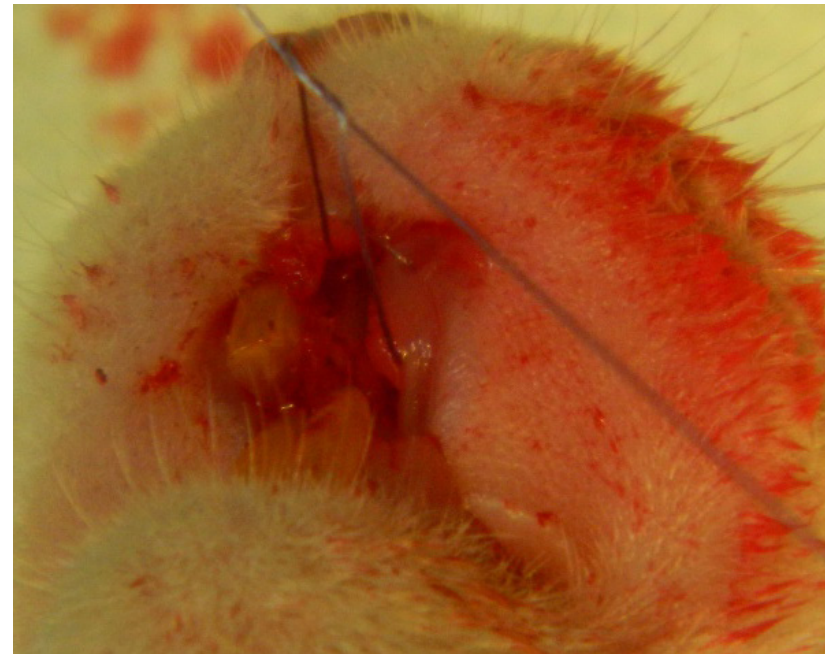

Figure 16. Intraoral post-surgical post-surgical suture suture 3.0 resorbable

(ALP U / L). Thus, 14 days after administration, values higher than the 7-day and 30-day intervals were recorded.

The control group in the case of blood alkaline phosphatase samples (PAL U / L) showed a gradual increase in values over the three time intervals.

It is noted that creatinine levels $(\mathrm{mg} / \mathrm{dl}$ ) are decreasing at 7,14 , and at 30 days there is a slight increase in this value under conditions of osteoporosis induced, which means that the administration of the acid ibandronic also makes changes on this blood sample.

Administration of denosumab (Prolia) in group 2 has oscillating levels of creatinine (mg / dl) values. Thus, 7 days after administration, values higher than the 14-day and 30-day intervals were recorded.

The control group (group 3) in the case of blood creatinine samples (mg / dl) showed oscillating values. The 7-day interval recorded the highest values, as to 14 days to decrease and to 30 days to slightly increase the values.

Summarizing all of these data, we can say that the two types of bisphosphonates (ibandronic acid, denosumab) administered under induced osteoporosis produce blood changes in alkaline phosphatase and creatinine, with changes in their values. From the radiological point of view, the occurrence of bony callus formation was observed, especially in the humerus, but also the bone necrosis at the level of the postextractional alveoli.

The use of bisphosphonates in the treatment of osteoporosis had a profound beneficial effect 


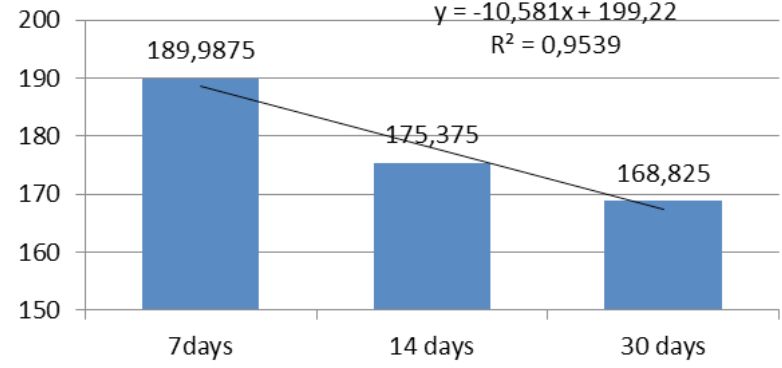

Figure 17. ALP (U / L) - Changes to 7, 14, 30 days at the administration of ibandronic acid group 1 (OSAGRAND)

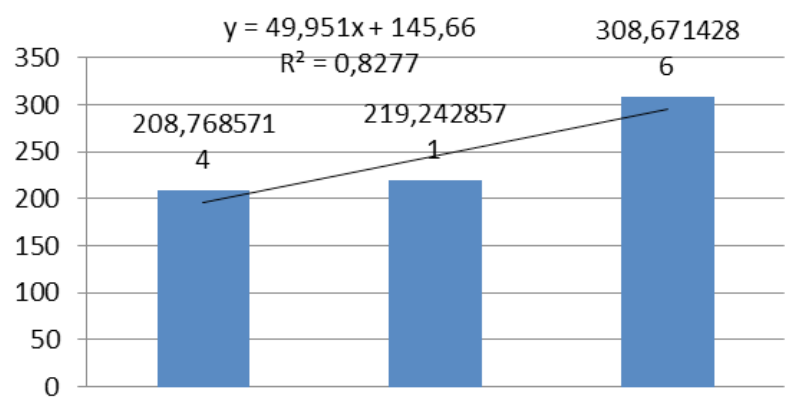

Figure 19. ALP (U / L) - changes at 7, 14, 30 days group 3 on physiological serum

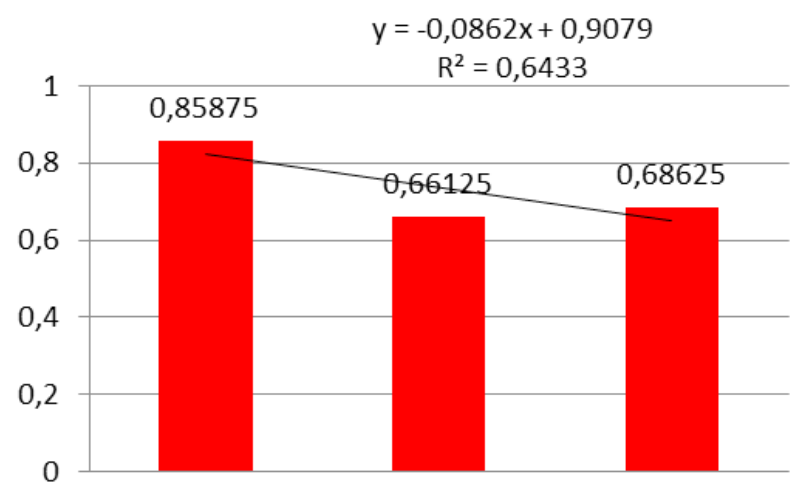

Figure 21. Creatinine - Changes at 7, 14, 30 days, group 2 administration of denosumab (PROLIA)

on the management of this pathological entity in postmenopausal women, and implicitly in the reduction of bone mass loss, minimizing the risk of fractures in this category of patients (Fleisch 1999, Bergston 2000). In the treatment of osteoporosis in postmenopausal women, bisphosphonates are elective in stopping osteoclast activity and implicitly in reducing bone turnover translated by rarefaction of bone architecture. Their administration i.v has both strengths

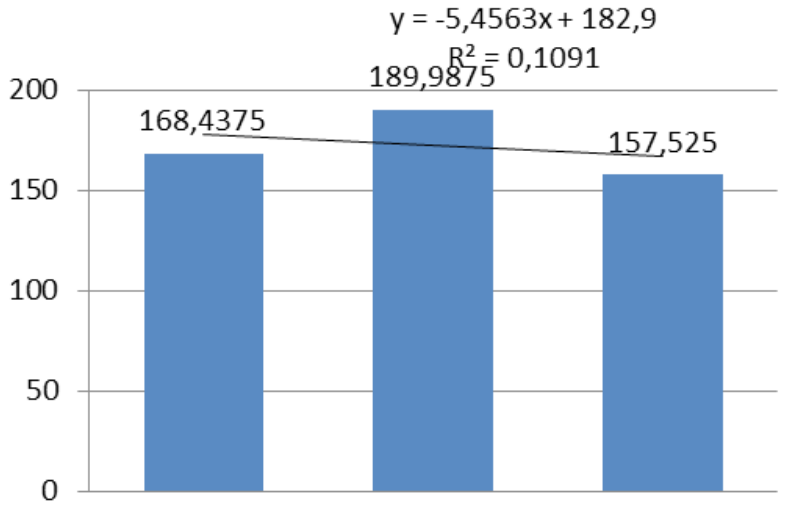

Figure 18. ALP (U / L) - Changes to 7, 14, 30 days, at the administration of denosumab group 2 (PROLIA)

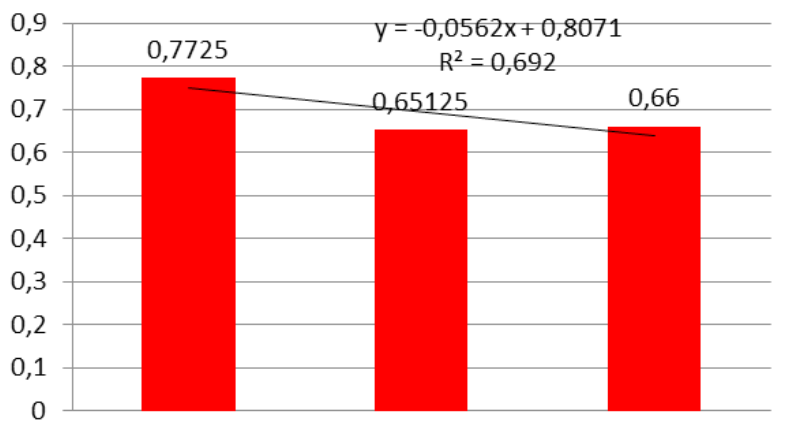

Figure 20. Creatinine - Changes at 7, 14, 30 days, group 1 administration of Ibandronic Acid (OSAGRAND)

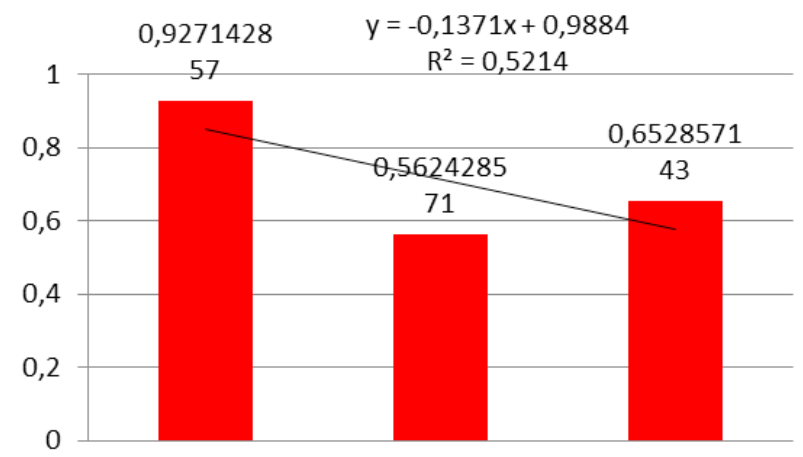

Figure 22. Creatinine - Changes at 7, 14, 30 days, group 3 (control) on administration of physiological serum

and disadvantages (Coxon et al., 2004; Malden 2007; Graham et al., 2000; Graham et al., 2011). According to our experiment, administration of bisphosphonates has antibacterial effects, decreased bone resorption and, implicitly, decreased osteoclast activity. This is beneficial to postmenopausal osteoporosis patients who have received ibandronic acid or denosumab under dental surgeries (dental extractions). It has been shown that denosumab with ibandronic acid has 
Table 1. Centralization of data regarding ALP and Creatinine values; general normal values at 7 days

\begin{tabular}{ccc}
\hline \multicolumn{1}{c}{ 7 days } & & \\
\hline Group 1 & & 0.7725 \\
\hline Mean & 189.9875 & 0.091612538 \\
\hline Standard deviation & 42.39327566 & 0.85875 \\
\hline Group 2 & 168.4375 & 0.115317884 \\
\hline Mean & 61.24316726 & \\
\hline Standard deviation & & 0.927142857 \\
\hline Group 3 & 208.7685714 & 0.087123339 \\
\hline Mean & 75.68864896 & 0.9 \\
\hline Standard deviation & & 130 \\
\hline Normal values & & \\
\hline
\end{tabular}

Table 2. Centralization of data regarding alkaline phosphatase and creatinine values; general normal values at 14 days

\begin{tabular}{ccc}
\hline \multicolumn{1}{c}{ 14 days } & & \\
\hline Group 1 & & \\
\hline Mean & 175.375 & 0.65125 \\
\hline Standard deviation & 64.5925637 & 0.051944338 \\
\hline Group 2 & 189.9875 & 0.66125 \\
\hline Mean & 70.16711557 & 0.054625347 \\
\hline Standard deviation & & \\
\hline Group 3 & 219.2428571 & 0.562428571 \\
\hline Mean & 69.45019456 & 0.234274666 \\
\hline Standard deviation & & 0.9 \\
\hline Normal values & & \\
\hline
\end{tabular}

stronger antiseptic effects, and dental extractions in these situations can be successfully performed without the occurrence of septic complications or local bone necrosis. Thus, denosumab (PROLIA) is a new generation bisphosphonate which, compared to ibandronic acid, has beneficial local and general effects, the risk of secondary effects and complications being less pronounced.

In our experiment on females in which osteoporosis was induced by ovariectomy, they were divided into three groups and then two types of bisphosphonates (ibandronic acid, denosumab) were administered, then dental extractions (extraction The upper central incisor for each rat in each batch) thus wishing to observe the occurrence of bone necrosis at the level of the postoperative alveoli. From the point of view of other similar experiments in the literature, speculations have also been made regarding the pathogenic role of certain strains of microorganisms such as Actinomycetes and the occurrence of bone osteonecrosis (53). Another study on the pathogenesis of bone osteonecrosis associated with bisphosphonate treatment suggested that seminal soft tissue is affected semiologically. On this basis, the authors concluded that any bone injury caused by local surgical procedures or other local trauma results in the release of a 
Table 3. Centralization of data regarding alkaline phosphatase and creatinine values; general normal values at 30 days

\begin{tabular}{ccc}
\hline \multicolumn{1}{c}{$\mathbf{3 0}$ days } & & \\
\hline Group 1 & & 0.66 \\
\hline Mean & 168.825 & 0.046904158 \\
\hline Standard deviation & 53.6036446 & \\
\hline Group 2 & 157.525 & 0.68625 \\
\hline Mean & 80.87729242 & 0.071900228 \\
\hline Standard deviation & & \\
\hline Group 3 & 308.6714286 & 0.652857143 \\
\hline Mean & 132.4988517 & 0.054989176 \\
\hline Standard deviation & & 0.9 \\
\hline Normal values & 130 & \\
\hline
\end{tabular}

certain amount of bisphosphonates in periodontal tissues. This release of bisphosphonates is toxic to the local epithelium and ultimately results in inhibition of local cell proliferation and implicitly a poor postoperative healing. Thus, these lesions provide an entry gate for oral microflora, which by local pathologic action leads to bone infections and bone necrosis (Ridley 1992). New generation bisphosphonates by the experiment on rats revealed that denosumab (Prolia) has local antibacterial effects over other bisphosphonates (ibandronic acid). Thus, administration of the two types of bisphosphonates not only resulted in a decrease in bone marrow extraction, but also the thickening of the hard lamina with the formation of bone callus, a reduction in bone resorption, antibacterial effects in the dental extraction conditions and implicitly a reduction of the purulent material at the level Postextractional alveolial, decrease in osteoclast number. All these aspects compared to the control group that received only saline.

This study provides preliminary observations of bone osteonecrosis in rats with osteoporosis induced in which the two types of bisphosphonates were administered and the monitoring of the biological and blood parameters in these circumstances. Thus, rats have more accelerated metabolism than humans, and although we have noticed the beneficial and harmful effects of these types of drugs, future studies should be done to determine their antibacterial effect. This model could serve as a starting point for studies with a similar theme for accurately defining the mechanism of action of the two types of bisphosphonates and their antibacterial effects as well as potential pathways in therapeutic interventions.

\section{Conclusions}

In the treatment of osteoporosis in postmenopausal women, bisphosphonates are elected in stopping osteoclast activity and implicitly in reducing bone turnover translated by re-shaping bone architecture. Their administration i.v has both strengths and disadvantages (Fleisch 1999; Berston 2000; Zhany et al., 1996; Ridley 1992; Frith et al., 2001). According to our experiment, administration of bisphosphonates has antibacterial effects, decreased bone resorption and, implicitly, decreased osteoclast activity. This is beneficial to postmenopausal osteoporosis patients who have received ibandronic acid or denosumab under dental surgeries (dental extractions). It has been demonstrated that denosumab with ibandronic acid has stronger antiseptic effects, and dental extractions in these situations can be performed successfully without the occurrence of septic complications or local bone necrosis. Thus, denosumab (PROLIA) is a new generation bisphosphonate which, compared to ibandronic acid, has beneficial local and general effects, the risk of secondary effects and complications being less pronounced. 
Acknowledgements: This research did not receive any specific grant from funding agencies in the public, commercial, or not-for-profit sectors. This experiment is part of the author's doctoral research. The author would like to express her sincere thanks to the whole team of the Faculty of Veterinary Medicine Cluj-Napoca, who helped with this experiment.

\section{References:}

1. Assouline-Dayan Y, Chang C, Greenspan A, Shoenfeld Y, Gershwin ME (2002). Pathogenesis and natural history of osteonecrosis. Semin Arthritis Rheum, 32: 94-124.

2. Bekker PJ, Holloway DL, Rasmessen AS, Murphy R, Martin SW, Leese PT, Holmes GB, Dunstan CR, DePaoli AM (2004). A single dose placebo-controled study of AMG 162, a fully human monoclonal antibody to RANKL, in postmenopausal women. J Bone Miner Res, 19: 10591066.

3. Bergston JD, Bostedor RG, Masarachia PJ, Reszka AA, Rodan G (2000). Alendronate is a specific nanomolar inhibitor of farnesyl diphosphate syntase. Arch Biochem Biophys, 373: 231-241.

4. Bilezikian JP (2006). Osteonecrosis of the jaw-do bisphosphonates pose a risk? N Engl J Med, 355: 22782281.

5. Bone HG, Bolognese MA, Yuen CK, Kendler DL, Wang H, Liu Y, San Martin J (2008). Effects of denosumab on bone mineral density and bone turnover in postmenopausal women. J Clin Endocrinol Metab, 93: 2149-2157.

6. Boyde A, Kashemirov BA, Mckenna CE, Graham R, Russel G (2001). The relationship between the chemistry and biological activity of the bisphosphonates, Bone, 49: 2033.

7. Capsoni F, Longhi M, Weinstein R (2006). Bisphosphonateassociated osteonecrosis of the jaw: The rheumatologists role. Arthritis Res Thes, 8: 219.

8. Conte-Neto N, Bastos AS, Chierici Marcantonio RA, Marcantonio Jr E (2012). Epidemiological aspects of rheumatoid arthritis patients affected by oral bisphosphonate-related osteonecrosis of the jaws. Head Face Med, 8: 5.

9. Coxon JP, Oades GM, Colston KW, Kirby RS (2004). Advances in the use of bisphosphonates in the prostate cancer setting. Prostate Cancer and Prostatic Diseases, 7: 99-104.

10. Coxon JP, Oades GM, Colston KW, Kirby RS (2004). Advances in the use of bisphosphonates in the prostate cancer setting. Prostate Cancer and Prostatic Diseases, 7: 99-104.

11. Del Castillo JL, García de Marcos JA, Arroyo Rodríguez S, Galdeano Arenas M, Calderón Polanco J (2007). Osteonecrosis de los maxilares asociada al empleo de bifosfonatos Bisphosphonate-associated osteonecrosis of the jaw. Rev Esp Cir Oral y Maxilofac, 29: 295-308.

12. Dileep S, Ivanovski S, Slevin M, HamletS, Pop TS, Brinzaniuc K, Petcu EB, Miroiu RI (2013). Bisphosphonate-related osteonecrosis of jaw (BRONJ): diagnostic criteria and possible pathogenic mechanisms of an unexpected antiangiogenic side effect. Vascular Cell, 5:1.

13. Ebetino FH, Hogan AML, Sun S, Tsoumpra MK, Duan X, Triffitt JT, Kwassi AA, Dunford JE, Barnett BL, Oppermann U, Lundy MW, Boyde A, Kashemirov BA, McKenna CE, Russell RGG (2011). The relationship between the chemistry and biological activity of the bisphosphonates. Bone, 49: 20-33.

14. FDA Briefing Document, Bezlotoxumab Injection. Meeting of the Antimicrobial Drugs Advisory Committee (AMDAC) (2016).

15. Federico II S Ferrara, L Califano (2010). From de Senectute. Current perspectives in the management of patients with drug-induced osteonecrosis of the maxilla: experience of the school of Naples. BMC Geriatrics, 10(Suppl 1): A56

16. Fischbach F (2009). Chemistry Studies. In A Manual of Laboratory and Diagnostic Tests. (8th ed.) (pp. 413-415). USA: Lippincott Williams \& Wilkins.

17. Fleisch H (1999). Bisphosphonate in bone disease. From the laboratory to the patient. (3th ed.). New York: The Parthenon Publishing Group.

18. Frith JC, Monkkonen J, Auriola S, Monkkonen H, Rogers MJ (2001). The molecular mechanism of action of the antiresorbtive and anti-inflamatory drug clodronateevidence for the formation in vivo of the metabolite that inhibits bone resobtion and causes osteoclast and macrophage apoptosis. Arthritis Reheum, 44: 2201-2210.

19. Genant HK, Engelke K, Hanley DA, Brown JP, Omizo M, Bone HG, Kivitz AJ, Fuerst T, Wang H, Austin M, Libanati C (2010). Denosumab improves density and strength parameters as measured by QCT of the radius in postmenopausal women with low bone mineral density. Bone. 47:131-139.

20. Graham R, Russell G (2016). Bisphosphonates: Mode of Action and Pharmacology, Botnar Research Centre and Oxford University Institute of Musculoskeletal Sciences, Oxford, United Kingdom, pp. 150-157.

21. Graham R, Russell G, Hellstein JW, Kalma JR (2011). Bisphosphonates: The first 40years. Bone, 49(1): 2-19.

22. Laboratory Corporation of America. Directory of Services and Interpretive Guide. Alkaline Phosphatase, Serum (2010). www.labcorp.com.

23. Lazar AC, Ilea A, Onisor F, Bel L, Sarpatoczi O, Purdoiu R, Papuc I, Taulescu M, Pacurar M, Campian RS (2016). Effects of bisphosphonates on the jaw bone in dental extractions - histological and biochemical aspects in an animal model. Revista de Chimie, 67: 692-695.

24. Lewiecki EM (2010). Denosumab- an emerging treatment for postmenopausal osteoporosis. Expert Opin Biol Ther., 10: 467-476.

25. Lima V, Goes P, Melo IM, Lima APS, Dutra CS (2012). Effect of alendronate on bone-specific alkaline phosphatase on periodontal bone loss in rats. Archives of Oral Biology, 57: 15371544.

26. Lipton A (2004). Toward new horizons: the future of bisphosphonate therapy. Oncologis, 9: 38-47. 
27. Lothar $\mathrm{T}$ (1998). Kidney and urinary tract. In Lothar $\mathrm{T}$ (Ed.), Clinical Laboratory Diagnostics use and assessment of clinical laboratory result (1st ed.) (pp. 366-370,375). Germany, Frankfurt am Main: TH-Books.

28. Malden NJ, Pai AY (2007). Oral bisphosphonate associated osteonecrosis of the jaws: three case reports. British Dental Journal, 203: 93-96.

29. Marx RE (2003). Pamidronate (Aredia) and zoledronate (Zometa) induced avascular necrosis of the jaws: A growing epidemic. J Oral Maxillofac Surg, 61:1115-1117.

30. McClung MR, Lewiecki EM, Cohen SB, et al. (2006). Denosumab in postmenopausal women with low bone mineral density. N Engl J Med, 354: 821-831.

31. Melton III LJ, Chrischilles EA, Cooper C, Lane AW, Riggs BL (1992). Perspective. How many women have osteoporosis? J Bone Miner Res, 7: 1005-1010.

32. Miller PD1, Bolognese MA, Lewiecki EM, McClung MR, Ding B, Austin M, Liu Y, San Martin J (2008). Effects of denosumab on bone density and turnover in postmenopausal women with low bone mass after longterm continued, discontinued and restarting of therapy: a randomized blinded phase 2 clinical trial. Bone, 43: 222229.

33. Mulligan R, Sobel S (2005). Osteoporosis: diagnostic testing, interpretation, and correlations with oral healthimplications for dentistry. Dent Clin North Am, 49: 463-484.

34. Petcu EB, Ivanovski S, Wright RG, Slevin M, Miroiu RI, Brinzaniuc K (2012). Bisphosphonate-related osteonecrosis of jaw (BRONJ): an anti-angiogenic sideeffect? Diagnostic Pathology, 7: 78.

35. Pichardo SEC, Kuypers SCC, van Merkesteyn JPR (2013). Denosumab osteonecrosis of the manible: A new entity? A case report. Journal of Cranio-Maxilo-Facial Surgery, 41: e65-e69.

36. Pighon A, Barsalani R, Yasari S, Prud'homme D, Lavoie JM (2010). Does exercise training prior to ovariectomy protect against liver and adipocyte fat accumulation in rats? Climacteric, 13: 238-248.

37. Ridley AJ, Hall A (1992). The small GTP-binding protein rho regulates the assembly of focal adhesions and action stress fibers in response to growth-factors. Cell, 70: 389399.

38. Sahni M, Collin P, Felix R, Fleisch H (1992). Direct effect of bisphosphonates on isolated rat osteoclasts. J Bone Miner Res, 17: 189.

39. Sankar P, Veena P, Suresh Kumar RV, Dhana Lakshmi N, Kokila S (2014). Ovariectomy in forty rats (Rattus norvegicus). Indian J. Anim. Res, 48: 516-517.
40. Sanna G, Preda L, Bruschini R, Cossu Rocca M, Ferretti S, Adamoli L, Verri E, Franceschelli L, Goldhirsch1A, Nole $F$ (2006). Bisphosphonates and jaw osteonecrosis in patients with advanced breast cancer. Annals of Oncology, 17: 1512-1516.

41. Sarasquete ME, Gonzalez M, San Miguel JF, Garcia-Sanz R (2009). Bisphosphonate-related osteonecrosis: genetic and acquired risk factors. Oral Disease, 15: 382-387.

42. Tipton DA, Seshul BA, Dabbous MK (2011). Effect of bisphosphonates on human gingival fibroblast production of mediators of osteoclastogenesis: RANK, Osteoprotegrin and interleukin-6. J Periodontal Res, 46: 39-47.

43. Torres SR, Chen CSK, Leroux BG, Lee PP, Hollender LG, Schubert MM (2011). Fractal dimension evaluation of cone beam computed tomography in patients with bisphosphonate-associated osteonecrosis. Dentomaxillofacial Radiology, 40: 501-505.

44. Van Breukelen FJ, Bijvoet OL, Frijlink WB, Sleeboom HP, Mulder H, van Oosterom AT (1982). Efficacy of aminohydroxypropylidene bisphosphonate in hypercalcemia: observations on regulation of serum calcium. Calcif Tissue Int, 34: 321-327.

45. Van den Wyngaert T, Huizing MT,Vermorken JB (2006). Bisphosphonates and osteonecrosis of the jaw: Cause and effect or a post hoc fallacy? Ann Oncol, 17: 1197-1204.

46. Wallach J (2001). Analizele de sange. In Interpretarea testelor de diagnostic. (7th ed.) (pp. 68-69; 73-76). Romania: Editura Stiintelor Medicale.

47. Whyte MP (2010). Physiological role of alkaline phosphatase explored in hypophosphatasia. Annals of the New York Academy of Science, 1192: 190-200.

48. Wilde F, Heufelder M, Lorenz K, Liese S, Liese J, Helmrich J, Schramm A, Hemprich A, Hirsch E, Winter K (2012). Prevalence of cone beam computed tomography imaging findings according to the clinical stage of bisphosphonaterelated osteonecrosis of the jaw. Oral Surg Oral Med Oral Pathol Oral Radiol, 114: 804-811.

49. Wilfried K, Durr UM. Klinische Laborator diagnostik in der medizin, ed. Schattaun 2005-2006, Komplet aktuallierte und erweiterte auflage, 482-483.

50. Yamashita J, McCauley LK (2012). Antiresorptives and Osteonecrosis of the Jaw. J Evid Base Dent Pract, S1: 233247.

51. Zhany FL, Casey PJ (1996). Protein prenylation: molecular mechanism and functional consequences. Am Rev Biochem, 65: 241-269. 